\title{
An Assessment of Domestic Financing for Reproductive, Maternal, Neonatal and Child Health in Sub-Saharan Africa: Potential Gains and Fiscal Space
}

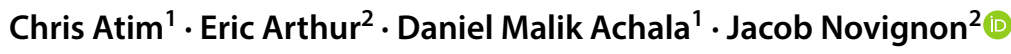

Published online: 12 September 2019

(c) The Author(s) 2020, corrected publication 2020

\begin{abstract}
Background Reproductive, maternal, neonatal and child health (RMNCH) remains an important public health objective. In sub-Saharan Africa (SSA), inadequate financial commitment continues to pose a major challenge to improving RMNCH outcomes. Understanding financing gains and potential fiscal space for RMNCH can therefore not be overemphasized.

Objective This study sought to analyse the potential gains from increased domestic financing as a source for improving RMNCH outcomes in SSA. We also assessed, in addition to the potential gains, the potential fiscal space available for financing RMNCH in SSA.

Methods Our study used panel econometric techniques to estimate gains from increased health financing in terms of RMNCH. We also reviewed tax system performance as well as debt sustainability to identify fiscal space potentials across countries.

Results We found significant gains from both domestic and external financing. The estimated elasticities suggest that the gains from domestic public financing were much stronger. The fiscal space options identified include tax revenue performance improvements, improved public financial management, and borrowing, at least in the short to medium term. The results show that fiscal space from improved tax systems ranged from US\$34.6 per capita in Uganda to US\$310.6 per capita in Nigeria. Conclusion This result reinforces calls for increased domestic financing for health through innovations in domestic resource mobilization. Improving the performance of tax systems will be a step in the right direction, with possible long-term gains to the health sector.
\end{abstract}

\section{Key Points for Decision Makers}

Our results show that reproductive, maternal, neonatal and child health gains from domestic public health financing were strong, with a potentially significant reduction in child and maternal mortality due to increased financing, all other things being equal.

We found potential fiscal space from improving public financial management, with emphasis on the efficiency and effectiveness of tax collection.

Borrowing to create fiscal space for the health sector was only feasible in the short term as debt burden was not sustainable in SSA countries.

Jacob Novignon

jnovignon@knust.edu.gh

1 African Health Economics and Policy Association (AfHEA), Accra, Ghana

2 Department of Economics, Kwame Nkrumah University of Science and Technology, Kumasi, Ghana

\section{Background}

Improvement in reproductive, maternal, neonatal and child health $(\mathrm{RMNCH})$ is an important public health objective and key performance indicator of a country's health sector. Despite efforts to improve these outcomes in the sub-Saharan Africa (SSA) region, the rates of maternal and neonatal deaths remain relatively high at 547 per 100,000 live births and 28.6 per 1000 live births, respectively, in 2017 [1]. Similarly, the region has relatively poor infant and child health outcomes. For instance, infant mortality in the region, which declined from 108.5 in 1990 to 56.4 per 1000 live births in 2015, is higher than the global average of 31.7 in 2015. In addition, while the under 5 years of age mortality rate declined from 180.9 to 83.2 per 1000 live births over the same period, it remains above the global average of 42.5 per 1000 live births [2].

This performance has prompted the international community to design and implement various initiatives and policies focused on improving RMNCH. ${ }^{1}$ For instance,

\footnotetext{
1 The economic literature suggests that investment in maternal and child health, and reproductive health in general, also affects general health, poverty reduction, and gender and social equity positively [33-36].
} 
the Millennium Development Goals (MDGs) era sought to reduce child mortality and improve maternal health by the year 2015. Most countries in SSA failed to achieve the set targets of reducing maternal deaths (by three-quarters) and child mortality (by two-thirds) between 1990 and 2015, even though significant progress was made in reducing child mortality compared with maternal mortality [3]. In a follow-up to the MDGs, the Sustainable Development Goals (SDGs) also set targets for improving maternal and child health by reducing maternal deaths and improving child health [4]. The launch of the Global Financing Facility (GFF) in support of the Every Woman Every Child movement, almost simultaneously with the launch of the SDGs, has more specifically focused attention on the financing gap and measures to raise domestic resources for funding reproductive, maternal, neonatal, child and adolescent health (RMNCAH).

The GFF has been necessitated by the recognition that adequate and consistent financing has been an important and persistent limitation to the achievement of goals and targets, such as those of the MDGs [5]. The achievement of the SDG goals hinges on sufficient financing for the health sector, in addition to other reforms at country level that affect $\mathrm{RMNCH}$ outcomes, such as those that remove financial and other barriers to health care for poor and vulnerable populations and promote investments in supply side improvements to enable effective and universal access to primary health care [6]. In this regard, recent global consensus (evidenced by the GFF and discussions around the financing of the SDGs before they were adopted) appears to have converged around domestic resource mobilization (DRM) as the principal source of raising revenues to ensure that adequate financing is available for country health systems.

This is an important shift from the MDGs era, where the implicit compact was that the developed countries would assist low-income and lower middle-income countries (LICs/LMICs) to achieve their goals and targets. Shifting the emphasis towards DRM is a recognition of the twin realities that foreign aid has been declining in recent times and that most of the resources that are generated for development do actually come from domestic sources in most developing countries. Putting increased emphasis on the role of DRM should therefore encourage even greater ownership of their development processes by the LICs and LMICs. DRM is defined by the World Bank as "increasing the flow of taxes and other income into government treasuries" [7], and by the European Commission as "the generation of government revenue from domestic resources, from tax or non-tax sources (royalties, licenses, levies or other income)" [8]. Against this backdrop, it is worth noting that the empirical literature is inconclusive regarding the effect of aid on health outcomes. Some studies have reported that foreign aid is ineffective in improving health outcomes [9-11], while others have reported a positive effect of aid on health outcomes [12, 13].

Monitoring financial resource flow for RMNCH was a central part of the Countdown [2], which sought to determine the funding gap between resources available and the actual investments required to reach MDG and national targets, and holding governments and the international community to account for investing adequately in the health of women and children [2]. Indeed, as alluded to by the Countdown, policy makers need financial information to make informed decisions on how best to allocate resources among competing needs, set priorities and ensure sustainable funding for programs aimed at improving $\mathrm{RMNCH}$ in SSA. In light of the need for sufficient financing for better RMNCH outcomes, it is important for governments and donors to have adequate health financing information that compares funding needs with the allocation of resources. This is important to enable policy makers plan and allocate resources efficiently to achieve the desired targets.

Against this backdrop, the current study sought to analyse the evidence on the potential impact of increased domestic financing for RMNCH in SSA. Specifically, we addressed two key research questions: (1) What are the potential RMNCH gains to be realized from increased health funding in SSA? (2) Is there potential fiscal space from domestic sources for RMNCH financing in SSA?

\section{Methods}

\subsection{Data Sources}

We relied on data from several sources. First, the National Health Accounts (NHA) data from various countries, captured by the Global Health Expenditure database available on the WHO website, was used. These data are a good source of disaggregated health expenditure. Second, we relied on estimates from reports of the Lancet Commission on Investing in Health $(\mathrm{CIH})$ to provide a broader appreciation of the resource requirements for financing RMNCH in SSA. We selected three LICs (Uganda, Rwanda and Ethiopia) and two $\mathrm{LMICs}^{2}$ (Nigeria and Kenya) based on data availability. Various data sources were explored for the fiscal space analysis, namely the International Monetary Fund (IMF) database (World Revenue Longitudinal Data, Government Financial Statistics and World Economic Outlook) and Public Expenditure and Financial Accountability (PEFA) reports.

\footnotetext{
${ }^{2}$ As classified by the World Bank.
} 


\subsection{Analytical Approach}

Each of the study research questions was tackled through different analytical procedures. To estimate the potential RMNCH gains from health financing, we estimated elasticities of domestic and external health financing on RMNCH outcomes in SSA. The elasticities show the changes in RNMCH that could be gained if health financing increased by $1 \%$. This analysis presents quantitative evidence of the marginal gains from increased health financing in SSA. Domestic health financing was disaggregated into government financing (gov), private health insurance ${ }^{3}$ (ins) and out-of-pocket expenditure (oop).

The econometric specification for this research question followed previous literature on the impact of health financing on health outcomes [10, 14-16]. We used Eqs. 1 and 2 to examine the impact of total donor health financing (aid) and disaggregated domestic financing on RMNCH outcomes.

$h_{i t}=\beta_{1} x_{i t}+\beta_{2} \operatorname{aid}_{i t}+v_{t}+\varepsilon_{i t}$,

$h_{i t}=\beta_{1} x_{i t}+\beta_{2} \operatorname{gov}_{i t}+\beta_{2}$ ins $_{i t}+\beta_{2} \mathrm{oop}_{i t}+\mu_{i}+\varepsilon_{i t}$,

where $h_{i t}$ indicates child and maternal health outcomes, $\mu_{i}$ captures country-specific characteristics that are unobserved and time invariant, $\varepsilon_{i t}$ is the standard error term, and $x_{i t}$ is a vector of control variables that influence RMNCH outcomes. These include country-specific variables that reflect economic, environmental and institutional situations that may influence health outcomes. These models were estimated using both fixed and random effects. We further conducted the Hausman specification test and confirmed the fixed effects model as the most appropriate.

In order to address the second research question, we first created a context for appreciating the extent of resource requirements for $\mathrm{RMNCH}$ financing by relying on the $\mathrm{CIH}$ reports that estimate the incremental cost of scaling up health investments for RMNCH $[17,18]$. Estimates for the five selected countries were extracted to support our argument of resource needs in SSA. The estimates show the level of resources required by countries to improve their health systems. Following this, we assessed the potential sources of fiscal space for domestic resource mobilization. Three broad channels were explored for potential fiscal space for $\mathrm{RMNCH}$, including public financial management effectiveness with a focus on tax administration and tax collection, tax effort and borrowing. These ideas are consistent with theoretical and empirical literature on fiscal space for health

\footnotetext{
${ }^{3}$ Comprises of private schemes financed through private premiums. The pool of financing is not administered through the government. This could also be complementary or substitutive.
}

[19-21]. First, we compared tax revenues as a percentage of gross domestic product (GDP) to a predetermined benchmark $^{4}$ of $20 \%$ for the years 2016 and 2017 . We then estimated the potential tax revenue that could be raised if tax revenues increased to $20 \%$. The estimates were then transformed in per capita terms. In assessing the performance of tax systems, we extracted the ratings of countries from the PEFA tool for assessing the status of public financial management. ${ }^{5}$. We also assessed debt sustainability using trend analysis of government revenue and expenditure. A converging trend suggests debt sustainability and potential source of revenue.

\section{Results}

\subsection{Econometric Results of Potential Reproductive, Maternal, Neonatal and Child Health (RMNCH) Gains from Increased Health Financing}

Table 1 presents regression results for the effect of external financing on RMNCH outcomes in SSA. The results also provide estimates of gains to RMNCH from increased external funding for the health sector. The summary statistics of the models suggest a good fit, implying that the results from the models are reliable. Estimates from the fixed-effects specification were reported following the Hausman specification test. All variables are reported in logs, hence the estimates can be interpreted as elasticities. The results indicate that donor financing has a negative and significant effect on RMNCH outcomes in SSA. Specifically, a $10 \%$ increase in external finance for health leads to a reduction in maternal mortality, under 5 years of age mortality, and infant mortality by approximately $0.2 \%, 0.3 \%$, and $0.3 \%$, respectively.

Table 2 shows the regression results for the effect of public and disaggregated private health expenditure on RMNCH outcomes. The relationship between public health expenditure and maternal mortality, under 5 years of age mortality, infant mortality and neonatal mortality was found to be negative and statistically significant across the estimated models. Accordingly, the estimated elasticities suggest gains, in terms of reduction, of approximately $0.6 \%, 1.5 \%, 1.2 \%$, and $0.8 \%$, respectively, if public health financing increased by $10 \%$. The effects of domestic financing are higher than those of external financing, reinforcing the case for increased emphasis on DRM for health financing.

\footnotetext{
4 Typically, LICs and LMICs collect taxes of between 10 and $20 \%$ of the GDP [37]. The $20 \%$ benchmark as suggested by the literature is the desirable $[23,37]$ and most realistically attainable rate by the LICs and LMICs in our study.

5 The PEFA tool and country reports can be accessed at https://pefa. org/region/sub-saharan-africa
} 
Table 1 External health financing effect on $\mathrm{RMNCH}$ outcomes

\begin{tabular}{|c|c|c|c|c|}
\hline Variables & MMR & U5M & IFM & NMR \\
\hline External health finance & $-0.017 * *(0.024)$ & $-0.033 * * *(0.026)$ & $-0.026^{* * *}(0.022)$ & $-0.009(0.018)$ \\
\hline Real GDP per capita & $-0.655^{* * *}(0.114)$ & $-0.506^{* * *}(0.146)$ & $-0.453 * * *(0.130)$ & $-0.226 * * *(0.082)$ \\
\hline Immunization (DPT) & $-0.006(0.050)$ & $-0.045(0.079)$ & $-0.015(0.062)$ & $-0.057 * * *(0.048)$ \\
\hline Sanitation & $-0.169 * *(0.146)$ & $-0.211 * * *(0.214)$ & $-0.147 * *(0.186)$ & $-0.212 * * *(0.138)$ \\
\hline HIV & $0.101 * * *(0.066)$ & $0.157 * * *(0.080)$ & $0.128 * * *(0.065)$ & $-0.004(0.042)$ \\
\hline Population (aged 15-64 years) & $-5.778 * * *(1.317)$ & $-1.025(1.337)$ & $-1.416^{* *}(1.085)$ & $0.777 *(1.048)$ \\
\hline Population (aged $>65$ years) & $-0.158(0.357)$ & $-0.495 * * *(0.327)$ & $-0.587 * * *(0.272)$ & $-0.171 * *(0.213)$ \\
\hline Population (aged < 14 years) & $-3.830 * * *(1.011)$ & $-0.713(1.052)$ & $-0.928 * *(0.907)$ & $0.733 * *(0.786)$ \\
\hline Urbanization & $-0.000(0.001)$ & $-0.001 * * *(0.001)$ & $-0.001 * * *(0.001)$ & $-0.001 * * *(0.001)$ \\
\hline Education (years) & $-0.128 * * *(0.091)$ & $-0.338 * * *(0.129)$ & $-0.281 * * *(0.115)$ & $-0.210 * * *(0.079)$ \\
\hline Constant & $49.940 * * *(9.099)$ & $18.620 * * *(9.636)$ & $19.560 * * *(8.040)$ & $1.735(7.324)$ \\
\hline Overall $R 2$ & 0.359 & 0.4286 & 0.3847 & 0.340 \\
\hline Wald test & $4367.450 * * *$ & $7536.870 * * *$ & $2909.660 * * *$ & $5829.450 * * *$ \\
\hline Hausman (Chi-square) & $59.790 * * *$ & $136.950 * * *$ & $132.820 * * *$ & $79.010 * * *$ \\
\hline No. of Observations & 652 & 652 & 652 & 652 \\
\hline No. of groups & 39 & 39 & 39 & 39 \\
\hline
\end{tabular}

Source: Authors' computation (MMR is maternal mortality per 100,000 live births; U5 M is under 5 years of age mortality per 1000 live births; IFM is infant mortality per 1000 live births; and NMR is neonatal mortality per 1000 live births)

Robust standard errors are reported in parentheses

$D P T$ Diphtheria, Pertussis, and Tetanus, GDP gross domestic product, IFM infant mortality rate, $M M R$ maternal mortality rate, $N M R$ neonatal maternal rate, $R M N C H$ reproductive, maternal, neonatal and child health, $U 5 M$ under 5 years of age mortality rate

***Significant at $1 \% ; * *$ Significant at $5 \%$; Significant at $10 \%$

\subsection{Analysis of Potential Fiscal Space for RNMCH}

To proceed with the fiscal space analysis, it is important to appreciate the extent of financing requirements for $\mathrm{RMNCH}$ in SSA. As noted earlier, this study relied on existing estimates from $\mathrm{CIH}$ reports to provide an appreciation of the financing requirements.

Tables 3 and 4 present the estimated incremental cost required for the health system to achieve the needed improvement in health outcomes by 2030 .

Table 3 presents estimates for selected LICs in SSA (Uganda, Rwanda and Ethiopia). The overall cost requirement for Uganda was approximately US $\$ 1.1$ billion in 2015 and is expected to increase slightly to approximately US $\$ 1.5$ billion in 2030. In Rwanda, the overall program cost was estimated to increase marginally from approximately US\$305 million in 2015 to US\$311 million in 2030. Interestingly, for Ethiopia, overall incremental cost declined marginally between 2015 (US $\$ 2.16$ billion) and 2030 (US\$2.14 billion). These figures suggest that, to meet the set SDG targets by 2030, each of these countries should increase their health expenditure by the amounts shown in Table 3 . This will translate to per capita expenditure of US\$27.34, US\$17.21 and US\$16.77 for Uganda, Rwanda and Ethiopia, respectively. A breakdown of the costs indicates that a total incremental cost of approximately US $\$ 112.7$ million,
US\$14.5 million and US\$218.3 million must be invested in RHMCH by Uganda, Rwanda and Ethiopia, respectively, by 2030 .

It can be observed that program costs rise in later years as incremental investments on health system strengthening (HSS) decline. This emphasizes the significant infrastructure needs of the health system in these countries. Indeed, this situation resonates across several LICs within the SSA region. Boyle et al. [18] noted that these HSS incremental investments are mostly made up of equipment and vehicles, and are vital for providing "a functional health system platform for service delivery that can tackle other long-term health challenges".

In Table 4, similar estimates are reported for countries that have recently graduated to lower middle-income status. Here, we present estimates for Kenya and Nigeria.

In Nigeria, the estimates show that an overall total of approximately US\$3.1 billion was needed as incremental cost for the health sector in 2015. This is expected to increase to US\$6.0 billion in 2030. In the case of Kenya, overall cost is expected to marginally increase from approximately US $\$ 1.2$ billion in 2015 to approximately US $\$ 1.5$ billion in 2030. The above estimates translate to an incremental per capita cost of approximately US $\$ 23.87$ and US $\$ 24.35$ for Nigeria and Kenya, respectively, by the year 2030. The breakdown of the costs suggests that for Kenya and Nigeria 
Table 2 Effect of domestic health financing on RMNCH outcomes

\begin{tabular}{|c|c|c|c|c|}
\hline Variables & MMR & $\mathrm{U} 5 \mathrm{M}$ & IFM & NMR \\
\hline Public health expenditure & $-0.067 * * *(0.042)$ & $-0.147 * * *(0.070)$ & $-0.117 * * *(0.064)$ & $-0.076 * * *(0.045)$ \\
\hline Out-of-pocket & $-0.116^{* * *}(0.042)$ & $-0.138 * * *(0.040)$ & $-0.133 * * *(0.039)$ & $-0.067 * * *(0.032)$ \\
\hline Private insurance & $-0.053 * * *(0.017)$ & $-0.063 * * *(0.027)$ & $-0.037 * * *(0.022)$ & $-0.007(0.026)$ \\
\hline Real GDP per capita & $-0.533 * * *(0.159)$ & $-0.187 * *(0.183)$ & $-0.150 * *(0.157)$ & $-0.086^{*}(0.101)$ \\
\hline Immunization (DPT) & $0.061 *(0.044)$ & $0.045(0.070)$ & $0.067 * *(0.049)$ & $-0.008(0.043)$ \\
\hline Sanitation & $-0.112(0.189)$ & $-0.213 * *(0.276)$ & $-0.166 * *(0.242)$ & $-0.251 * * *(0.179)$ \\
\hline HIV & $0.017(0.061)$ & $0.053 *(0.083)$ & $0.047 *(0.071)$ & $0.060 * * *(0.056)$ \\
\hline Population (aged 15-64 years) & $-3.488 * * *(1.578)$ & $2.360 * *(1.517)$ & $1.046(1.153)$ & $1.931 * * *(1.397)$ \\
\hline Population (aged $>65$ years) & $0.574 * * *(0.454)$ & $-0.010(0.404)$ & $-0.248^{*}(0.337)$ & $0.024(0.304)$ \\
\hline Population (aged $<14$ years) & $-2.128 * * *(1.125)$ & $1.386 * *(1.205)$ & $0.567(0.942)$ & $1.380 * * *(0.937)$ \\
\hline Urbanization & $-0.000(0.001)$ & $-0.002 * * *(0.001)$ & $-0.001 * * *(0.001)$ & $-0.001 * * *(0.001)$ \\
\hline Education (years) & $-0.196 * * *(0.129)$ & $-0.386^{* * *}(0.202)$ & $-0.289 * * *(0.187)$ & $-0.201 * * *(0.127)$ \\
\hline Constant & $32.880 * * *(10.200)$ & $-5.163(10.800)$ & $1.809(8.297)$ & $-6.367(9.266)$ \\
\hline Overall $R 2$ & 0.2957 & 0.477 & 0.420 & 0.375 \\
\hline Wald test & $26464.230 * * *$ & $3013.110 * * *$ & $0.000 * * *$ & $4427.400 * * *$ \\
\hline Hausman (Chi-square) & $53.780 * * *$ & $86.230 * * *$ & $91.860 * * *$ & $72.080 * * *$ \\
\hline No. of groups & $487(34)$ & $487(34)$ & $487(34)$ & $487(34)$ \\
\hline
\end{tabular}

Source: Authors' computation

Robust standard errors are reported in parenthesis. All variables were used in natural logs

$G D P$ gross domestic product, $I F M$ infant mortality rate, $M M R$ maternal mortality rate, $N M R$ neonatal maternal rate, $R M N C H$ reproductive, maternal, neonatal and child health, USM under 5 years of age mortality rate

***Significant at $1 \% ; *$ Significant at $5 \%$ * Significant at $10 \%$

Table 3 Annual incremental cost of the grand convergence investment case in low-income countries in sub-Saharan Africa

\begin{tabular}{|c|c|c|c|c|c|c|}
\hline \multirow[t]{3}{*}{ Category } & \multicolumn{6}{|c|}{ Incremental costs (US\$) } \\
\hline & \multicolumn{2}{|l|}{ Uganda } & \multicolumn{2}{|l|}{ Rwanda } & \multicolumn{2}{|l|}{ Ethiopia } \\
\hline & 2015 & 2030 & 2015 & 2030 & 2015 & 2030 \\
\hline \multicolumn{7}{|l|}{ RHMCH } \\
\hline Family planning & $7,675,739$ & $45,402,848$ & $2,288,040$ & $11,521,090$ & $12,341,741$ & $71,139,702$ \\
\hline Maternal and newborn health & $8,790,731$ & $33,588,220$ & $2,576,506$ & $10,766,224$ & $11,224,985$ & $111,034,734$ \\
\hline Immunization & $69,064,781$ & $67,754,907$ & $5,885,113$ & $(3,403,635)$ & $63,581,292$ & $46,508,215$ \\
\hline Treatment of childhood illness & $14,499,337$ & $11,327,146$ & $3,858,878$ & $7,096,105$ & $22,429,038$ & $60,796,153$ \\
\hline \multicolumn{7}{|l|}{ HIV/AIDS, TB, and malaria } \\
\hline Malaria commodities & $48,918,599$ & $68,563,840$ & $12,579,969$ & $15,312,901$ & $73,169,187$ & $102,600,454$ \\
\hline Other malaria costs & $55,656,896$ & $72,577,164$ & $8,659,717$ & $11,496,418$ & $32,300,206$ & $51,159,855$ \\
\hline TB treatment & $38,942,619$ & $28,748,048$ & $5,281,805$ & $3,757,749$ & $96,918,719$ & $51,452,752$ \\
\hline ART and PMTCT for HIV & $69,067,653$ & $283,058,775$ & $5,343,127$ & $18,261,619$ & $30,740,331$ & $37,635,974$ \\
\hline Other HIV costs & $56,151,742$ & $239,633,697$ & $3,369,035$ & $13,551,594$ & $24,272,972$ & $31,313,533$ \\
\hline Total program costs & $368,768,097$ & $850,654,646$ & $49,842,191$ & $88,360,066$ & $366,978,472$ & $563,641,372$ \\
\hline Population & $39,674,411$ & $56,543,748$ & $13,647,623$ & $18,107,034$ & $95,952,806$ & $127,717,596$ \\
\hline Cost per capita & 9.29 & 15.04 & 3.65 & 4.88 & 3.82 & 4.41 \\
\hline \multicolumn{7}{|l|}{ HSS } \\
\hline Incremental investment & $742,945,089$ & $695,026,633$ & $255,566,100$ & $223,190,741$ & $1,796,817,249$ & $1,577,823,263$ \\
\hline Total overall costs (including HSS) & $1,111,713,186$ & $1,545,681,279$ & $305,408,291$ & $311,550,807$ & $2,163,795,721$ & $2,141,464,635$ \\
\hline Cost per capita & 28.02 & 27.34 & 22.38 & 17.21 & 22.55 & 16.77 \\
\hline
\end{tabular}

Source: CIH estimates

ART antiretroviral therapy, $C I H$ Commission on Investing in Health, HSS health system strengthening, PMTCT Prevention of Mother-To-Child Transmission, $R M N C H$ reproductive, maternal, neonatal and child health, $T B$ tuberculosis 
Table 4 Annual incremental cost of the grand convergence investment case in lower-middle income countries in subSaharan Africa

\begin{tabular}{|c|c|c|c|c|}
\hline \multirow[t]{3}{*}{ Category } & \multicolumn{4}{|c|}{ Incremental costs (US\$) } \\
\hline & \multicolumn{2}{|l|}{ Nigeria } & \multicolumn{2}{|l|}{ Kenya } \\
\hline & 2015 & 2030 & 2015 & 2030 \\
\hline \multicolumn{5}{|l|}{ RHMCH } \\
\hline Family planning & $33,726,541$ & $299,626,950$ & $7,222,916$ & $32,944,251$ \\
\hline Maternal and newborn health & $161,220,516$ & $423,819,540$ & $11,666,725$ & $47,490,717$ \\
\hline Immunization & $182,858,213$ & $185,726,047$ & $26,047,780$ & $7,899,867$ \\
\hline Treatment of childhood illness & $115,956,890$ & $350,110,113$ & $16,555,473$ & $28,266,025$ \\
\hline \multicolumn{5}{|l|}{ HIV/AIDS, TB, and malaria } \\
\hline Malaria commodities & $279,262,146$ & $490,273,666$ & $20,425,078$ & $28,689,894$ \\
\hline Other malaria costs & $509,583,355$ & $1,089,252,415$ & $28,216,595$ & $44,004,999$ \\
\hline TB treatment & $100,852,160$ & $73,762,287$ & $61,456,910$ & $40,777,651$ \\
\hline ART and PMTCT for HIV & $231,576,920$ & $997,725,539$ & $64,492,780$ & $282,837,357$ \\
\hline Other HIV costs & $192,539,593$ & $857,569,498$ & $50,144,936$ & $238,404,963$ \\
\hline Total program costs & $1,807,576,335$ & $4,767,866,054$ & $286,229,192$ & $751,315,724$ \\
\hline Population & $184,170,039$ & $250,230,897$ & $47,100,786$ & $62,405,693$ \\
\hline Cost per capita & 9.81 & 19.05 & 6.08 & 12.04 \\
\hline \multicolumn{5}{|l|}{ HSS } \\
\hline Incremental investment & $1,336,401,380$ & $1,204,920,290$ & $882,011,775$ & $768,238,631$ \\
\hline Total overall costs (including HSS) & $3,143,977,715$ & $5,972,786,344$ & $1,168,240,967$ & $1,519,554,356$ \\
\hline Cost per capita & 17.07 & 23.87 & 24.80 & 24.35 \\
\hline
\end{tabular}

Source: CIH estimates

$A R T$ antiretroviral therapy, $C I H$ Commission on Investing in Health, HSS health system strengthening, PMTCT Prevention of Mother-To-Child Transmission, $R M N C H$ reproductive, maternal, neonatal and child health, $T B$ tuberculosis to attain health targets related to $\mathrm{RMNCH}$, there is a need to scale-up programs at an incremental cost of US\$959.7 million and US\$83.7 million, respectively.

We observe that while the proportion of programmatic scale-up mostly increased over the years in LICs, the rate of increase was much higher in LMICs. These distinctions have been attributed to the fact that LMICs already have relatively higher per capita investment, and hence achieved some leverage in HSS, compared with LICs.

The huge funding gaps discussed above underscore the need to increase domestic resource mobilization and allocation to the health sector if there could be significant progress towards achieving the health-related SDG targets in SSA. We now assess some sources of potential fiscal space for the health sector in SSA.

\subsubsection{Increasing Tax Revenue to Gross Domestic Product (GDP) Ratio}

Evidence shows that often, tax revenues as a percentage of GDP are relatively low in many LICs and LMICs, with nearly half of these countries having approximately $<15 \%$ of tax shares of their GDP as tax revenues [22-25]. In Table 5, we provide data on three indicators, namely tax revenue to GDP ratio, general revenue to GDP ratio, and the additional per capita tax revenue that could be raised if tax revenues increased to an often arbitrary but usually suggested benchmark of $20 \%$ of GDP [19, 23-26]. From Table 5, it is observed that with the exception of Kenya and Rwanda, which had tax revenue to GDP shares above $15 \%$, all the other countries in this study have tax revenues $<15 \%$ of GDP, lower than the $20 \%$ GDP benchmark [23, 25, 26].

Estimates of the potential fiscal space per capita (additional per capita revenues) that could be generated if tax shares of GDP increase to $20 \%$ of GDP are in the range of US\$31.9-359.9 in 2016, and US\$34.6-310.6 in 2017. Specifically, Nigeria emerges with the highest potential gains in both 2016 and 2017 . The country could raise approximately US\$360 and US\$311 additional revenue in 2016 and 2017, respectively, if tax revenue was increased to $20 \%$ of GDP. For most of these countries, potential fiscal space increased from 2016 to 2017, suggesting that tax revenue reduced over the period. The results of this analysis suggest that SSA countries have some potential for creating additional fiscal space to finance not only RMNCH investments towards achieving the SDGs but also funding for other government developmental activities. 
Table 5 Tax revenue performance and potential fiscal space $(2016 / 2017)$

\begin{tabular}{|c|c|c|c|c|c|c|}
\hline \multirow[t]{2}{*}{ Country } & \multicolumn{2}{|c|}{ Total revenue (\% of GDP) } & \multicolumn{2}{|c|}{ Tax revenue (\% of GDP) } & \multicolumn{2}{|c|}{$\begin{array}{l}\text { Potential fiscal space per } \\
\text { capita (US\$) }\end{array}$} \\
\hline & 2016 & 2017 & 2016 & 2017 & 2016 & 2017 \\
\hline Ethiopia & 15.88 & 14.90 & 12.36 & 11.63 & 59.38 & 68.40 \\
\hline Kenya & 18.73 & 18.27 & 15.94 & 15.80 & 63.32 & 71.25 \\
\hline Nigeria & 5.55 & 6.20 & 3.70 & 4.43 & 359.92 & 310.56 \\
\hline Rwanda & 23.46 & 22.86 & 15.66 & 15.53 & 31.92 & 34.58 \\
\hline Uganda & 14.99 & 15.03 & 13.10 & 13.36 & 46.72 & 46.64 \\
\hline
\end{tabular}

Source: Extracted from IMF World Revenue Longitudinal Data (2019) and the World Economic Outlook Database (2019)

Potential fiscal space was computed assuming a tax revenue increase to $20 \%$ of GDP $G D P$ gross domestic product, IMF International Monetary Fund

Table 6 Tax system performance and potential fiscal space

\begin{tabular}{|c|c|c|c|c|}
\hline \multirow[t]{2}{*}{ Indicator } & \multicolumn{4}{|l|}{ Country performance } \\
\hline & Kenya (2010/2011) & $\begin{array}{l}\text { Ethiopia } \\
(2012 / 2013)\end{array}$ & Rwanda (2013/2014) & $\begin{array}{l}\text { Uganda } \\
(2015 / 2016)\end{array}$ \\
\hline Tax payment collection effectiveness score & $\mathrm{D}+$ & $\mathrm{D}+$ & $\mathrm{D}$ & $\mathrm{B}$ \\
\hline Tax debt stock ${ }^{\mathrm{a}}$ & $85,919 \mathrm{~m}$ & $890 \mathrm{~m}$ & $102,655 \mathrm{~m}$ & $728 b$ \\
\hline Tax debt as a percentage of tax revenue & $17.8 \%$ & $1.2 \%$ & $13.3 \%$ & $3.6 \%$ \\
\hline Tax debt collection ratio & $15.1 \%$ & $92.2 \%$ & $24.7 \%$ & $46.8 \%$ \\
\hline Revenue administration score & NA & NA & $\mathrm{C}+$ & $\mathrm{B}$ \\
\hline Fiscal space through tax audits and reforms $\mathrm{s}^{\mathrm{a}}$ & $7.2 \mathrm{~b}$ & $8436 \mathrm{~m}$ & $20.1 \mathrm{~b}$ & $40 \mathrm{~b}$ \\
\hline
\end{tabular}

Source: Extracted from the Various Countries' PEFA Assessment Reports

No data were available on Nigeria

$N A$ not available

${ }^{a}$ Values are reported in millions (m) or billions (b) of local currency units

\subsubsection{Effectiveness of the Tax Collection System}

Table 5 presents data on tax revenue performance and potential fiscal space for selected countries [26, 27]. Given the enormous revenue potential outlined above, an important question is how these potentials could be realized. In this sub-section, we focus on possible areas that could be improved to realize this fiscal space potential. To do this, we relied on PEFA reports that assess public sector financial management practices across countries. We focus on three areas of assessment, namely tax administration and effectiveness of tax collection, tax arrears and tax arrears collections arising from tax reforms and audits.

It is generally observed that tax revenue administration, which encompasses several other components, including effectiveness of tax payment, collection and accountability for tax revenue, is a major fiscal space blockade in many SSA countries, particularly those analyzed in this study. As can be observed from Table 6 , almost all the countries in this study scored poorly in the PEFA assessment scores on effectiveness of tax collection. Again, tax arrears are increasingly limiting the fiscal space of these countries by denying the economies substantial resources in a given time frame. These tax arrears in the respective countries, if collected at the right time, could potentially help reduce, if not eliminate, the funding gaps not only in $\mathrm{RMNCH}$ programs but also other sectors of the economy. In fact, tax arrears range from $1.2 \%$ of total tax revenue (Ethiopia) to $17.8 \%$ of total tax revenue (Kenya). Even though the collection ratios of tax arrears have been improving gradually in recent times due to tax reforms and audits, this has generally been poor across the selected SSA countries.

\subsubsection{Borrowing for Health}

An alternative instrument for generating additional fiscal space to finance RMNCH and the health sector funding gap as a whole is for government to resort to borrowing 
Panel a: Expenditure \& Revenue Trend in Uganda

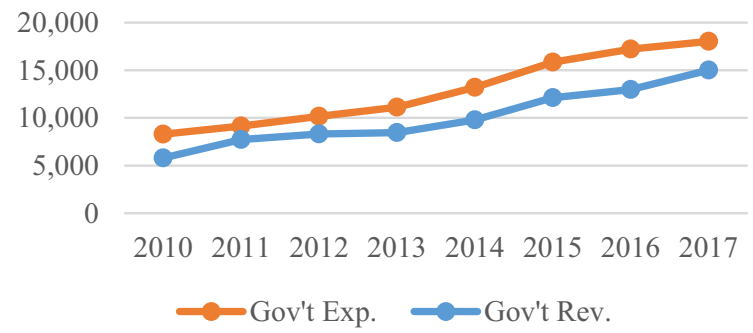

Panel c: Expenditure \& Revenue Trend in Ethiopia

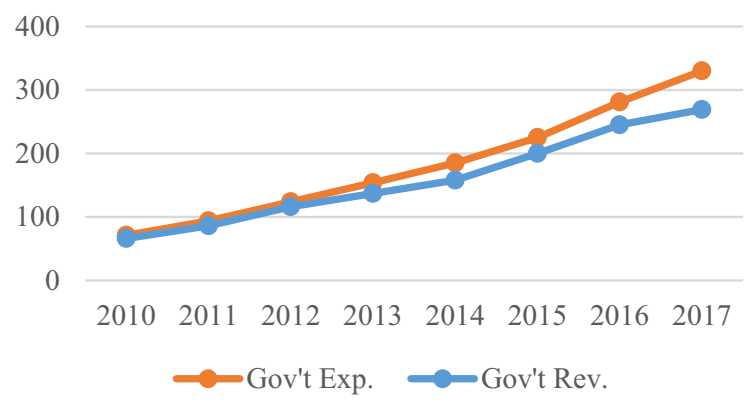

Panel e: Expenditure \& Revenue Trend in Nigeria

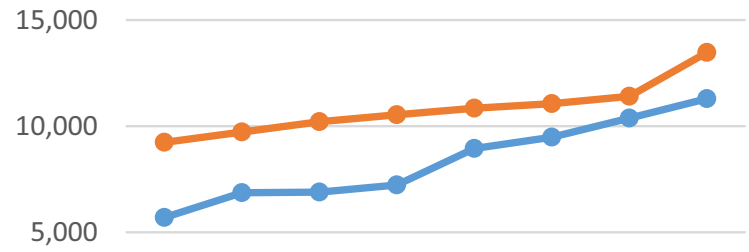

0

20102011201220132014201520162017 $\longrightarrow$ Gov't Exp. $\quad \longrightarrow$ Gov't Rev.

Fig. 1 Trends in government expenditures, revenues and debt. Source: Authors' computations using data from the IMF's Government Financial Statistics, 2018. Revenue and expenditure figures are reported in local currency units. Debt is measured as a percentage

either domestically or internationally. Health sector bonds are recent innovations for raising funds to finance critical health expenditures. However, the viability of this option largely depends on debt sustainability, as well as the general fiscal sustainability of the country [21]. We provide analysis of the viability of the option of borrowing as a possible fiscal space instrument for selected SSA countries in this study.

The sustainability indicators analyzed (debt sustainability and general fiscal space sustainability) are important determinants of the viability of borrowing as a potential
Panel b: Expenditure \& Revennue Trend in Rwanda

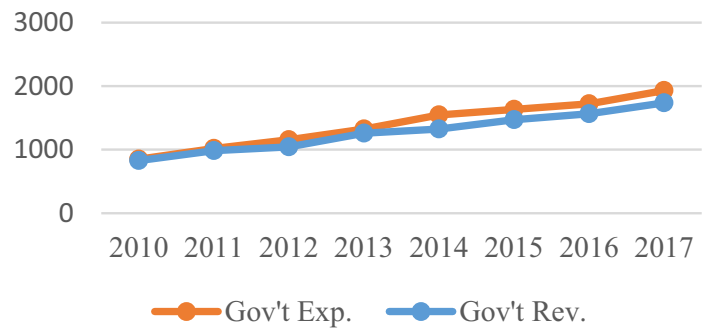

Panel d: Expenditure \& Revenue Trend in Kenya

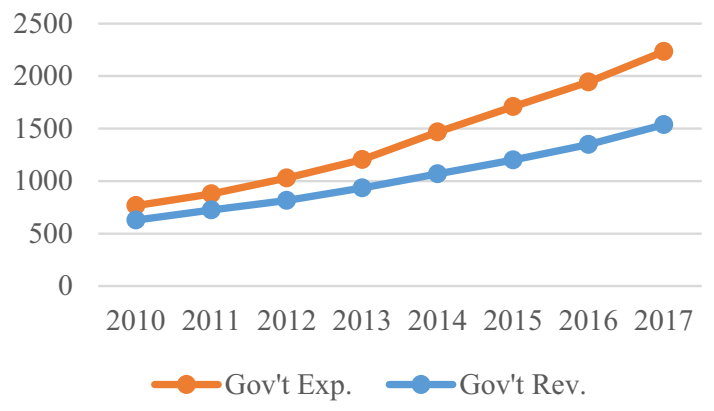

Panel f: Debt as \% of GDP in selected SSA Countries

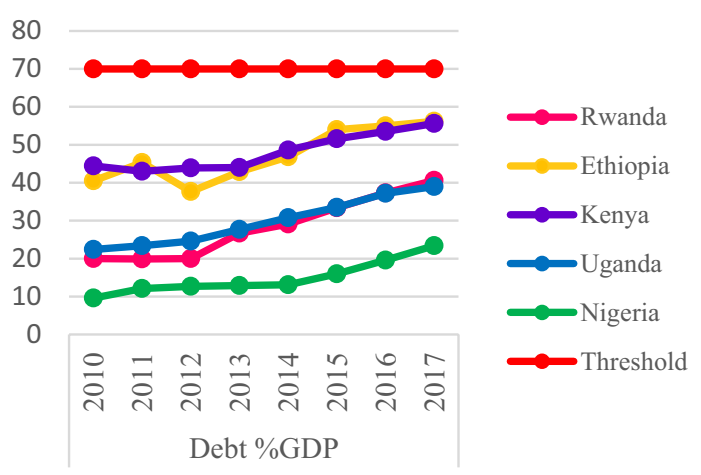

of GDP. Gov't Exp. government expenditure, Gov't Rev. government revenue, SSA sub-Saharan Africa, GDP gross domestic product, $I M F$ International Monetary Fund

fiscal space avenue for financing RMNCH. From the results obtained in Fig. 1, we observed that in all countries, expenditures lie above revenue. The gap between revenues and expenditures widens gradually along the years, indicating that in the long term, borrowing may not be a sustainable fiscal space option for financing RMNCH. In addition, all countries selected in this study are within the debt sustainability threshold of $70 \%$ of GDP. The results obtained suggest that borrowing is a viable potential fiscal space option for many SSA countries, at least in the short to medium 
term, especially if growth prospects are good. However, this option is not sustainable in the long term given the general trends in revenues and expenditures in these countries and the widening gap thereof.

\section{Discussion}

This study sought to provide answers to important questions about health financing in SSA. The specific focus of the study was on understanding the nature of health financing, gains from health financing, and potential fiscal space for health. There was consistent evidence that current health outcomes in the SSA region lag behind global targets such as the MDGs and the currently active SDGs. The extent of lag raises concerns about health financing challenges in SSA and emphasizes the need to scale-up interventions directed towards RMNCH outcomes.

Unfortunately, the data showed financial commitment to the health sector, especially from domestic sources [1]. Donor resources also looked very well stretched and disbursements were mostly directed to programmatic costs, and earmarked for interventions that are in line with donors' objectives, suggesting the responsibility of HSS falls on governments. This supports calls for innovative domestic financing for the health sector. In recent years, countries have been encouraged to take responsibility for the health sector by committing to funding from domestic sources [23].

While calls for increased health financing seem valid, there may be some significant non-financial factors that impede the achievement of health targets, especially for maternal health. Some have pointed to cultural factors, additional financial barriers beyond the health facility costs, and issues to do with ambulance availability, blood banks, and timeliness of transfers from home to facilities where lifesaving assistance might be available [20,21]. For instance, the recent holistic assessment of Ghana's health sector shows dramatic improvement in assisted delivery, but the maternal mortality ratio has been stagnant at best and institutional delivery has become a bit worse. These factors seem to have particular resonance in rural communities, where the rate of assisted delivery usually lags well behind that of the urban areas [28].

The econometric results showed significant gains from both domestic and donor financing, with the former being more pronounced than the latter. Results from this study indicate that domestic health financing in particular has a significant and negative impact on RMNCH in SSA.

These findings are consistent with existing literature [29, $30]$. In the case of private financing, although a disaggregated analysis suggests that out-of-pocket expenditure and private insurance both significantly reduce $\mathrm{RMNCH}$ mortality, these methods have well-known negative effects on access and equity, and are not recommended as major policies to be pursued as a means of achieving any of the priority objectives in the health sector. Such private financing methods could be catastrophic and should be minimized as much as possible. Recent calls to scale-up Universal health coverage (UHC) across countries in the region underscore this concern [31, 32].

The incremental cost estimates suggest that to leverage gains of this nature, governments must commit further resources. The estimates show that for the countries included in this study, incremental costs range between US\$225 million and US $\$ 1.7$ billion by the year 2030, when the SDG targets will be due. An important aspect of these additional resource requirements is their feasibility. The health sector in developing countries compete with other sectors for the available limited resources. The question is whether or not these LICs and LMICs can afford to oblige with these requirements. Using projected GDP for these countries, we estimate that, for most of these countries, incremental cost will form $<1 \%$ of GDP by 2020 . Only Uganda is expected to increase health expenditure by an additional $1.94 \%$ of GDP.

The foregoing emphasizes the need for additional fiscal space to be created for the health sector. Our estimates suggest that improving public financial management and administration, as well as tax effort and borrowing, are good potential sources of fiscal space for RMNCH investments. While we recognize that increases in resource mobilization do not automatically translate into increased health expenditures, it has been suggested that generating national political priority for health, creating tax funds specifically for health, earmarking some proportion of tax revenue for health, and health spending decentralization are important steps for achieving increased health expenditures [22]. There was evidence of poor-performing tax systems in the selected LICs and LMICs. Some part of the additional resources that could be raised by better tax performance should be devoted to health sector programs directed towards $\mathrm{RMNCH}$.

\subsection{Limitations}

The scope and nature of this study was limited by a number of constraints. First, the data requirement for research questions of this nature are complex. While we attempted to answer the questions with available data, we believe access to better health financing data would have enhanced the analysis. For instance, in estimating the health funding gap, several assumptions were made to ensure that the estimates are comparable across countries. Second, our analysis of fiscal space was only limited to tax system performance and administration, as well as public borrowing. As noted in the literature, there may be several other sources of fiscal space that were not explored in this study, mainly due to data 
limitation. In addition, our analysis of fiscal space does not account for underlying differences across countries in terms of macroeconomic performance. This may limit the extent to which our conclusions can be generalized. Finally, the generalizability of our findings is somewhat limited by the non-availability of relevant data for many SSA countries.

\section{Conclusions}

This study set out to assess health funding for RMNCH in SSA. The funding gaps were assessed, as well as potential gains from funding. In addition, the potential fiscal space for RMNCH was assessed to provide policy insights. In general, there was evidence of a significant funding gap for the health sector as a whole, and RMNCH in particular. We also found significant potential benefits from increased financing for RMNCH in SSA. Finally, two main areas were explored for fiscal space to the health sector. We identified improved tax administration and effectiveness as potential long-term sources of fiscal space, while borrowing may only be viable in the short to medium term. The findings highlight an important aspect of health financing, especially in developing countries. The need to increase investment in the health sector equally requires identifying fiscal space to raise enough government revenues. Improving tax systems and ensuring tax debts are redeemed will be an important step. In addition, strong advocacy and increased capacity of the health sectors to make a business case for increased health investments are required to help translate increased revenues into rising health sector expenditures. Finally, attaining improved $\mathrm{RMNCH}$ outcomes presupposes not only increased health sector spending but also, equally if not more importantly, the efficient use of allocated resources.

Acknowledgements The authors are grateful to Atakorah Yaw Boateng and Richard Ofori Boateng for the research support they provided. They also acknowledge the administrative and secretariat support received from the office of the African Health Economics and Policy Association (AfHEA).

Author Contributions CA and JN conceived the study and supervised the analysis; JN, EA and DMA undertook the analysis; and CA, JN, EA and DMA prepared the manuscript. All authors read and approved the final version submitted for publication.

Data Availability Statement All datasets used in this study are publicly available and can be assessed at the links provided below. All other information used for analysis are duly cited in the text. https:// stats.oecd.org/Index.aspx?DataSetCode=crs1. https://www.imf.org/en/ Data. http://datatopics.worldbank.org/world-development-indicators/. https://www.pefa.org/.

\section{Compliance with Ethical Standards}

Funding The authors received funding from the African Economic Research Consortium (AERC) (Grant no. RC17505) to support this study.

Conflict of interest Chris Atim, Eric Arthur, Daniel Malik Achala and Jacob Novignon, declare they have no conflicts of interest to report.

Open Access This article is licensed under a Creative Commons Attribution-NonCommercial 4.0 International License, which permits any non-commercial use, sharing, adaptation, distribution and reproduction in any medium or format, as long as you give appropriate credit to the original author(s) and the source, provide a link to the Creative Commons licence, and indicate if changes were made. The images or other third party material in this article are included in the article's Creative Commons licence, unless indicated otherwise in a credit line to the material. If material is not included in the article's Creative Commons licence and your intended use is not permitted by statutory regulation or exceeds the permitted use, you will need to obtain permission directly from the copyright holder. To view a copy of this licence, visit http://creativecommons.org/licenses/by-nc/4.0/.

\section{References}

1. World Bank Group. World development indicators. Washington, DC: World Bank Group; 2017.

2. World Health Organization. World health statistics. Geneva: World Health Organization; 2015.

3. United Nations. The sustainable development goals. New York: United Nations; 2015.

4. United Nations. The millennium development goals. New York: United Nations; 2015.

5. The Global Financing Facility 2016-2017 Annual Report. Country-Powered Investments for Every Woman, Every Child. Washington, DC: International Bank for Reconstruction and Development/The World Bank; 2017.

6. Musango L, Ota M. The critical role of health financing in progressing universal health coverage. Afr Monit. 2015;20:3-9.

7. World Bank. Domestic resource mobilization. Washington, DC: World Bank; 2016.

8. European Commission. Domestic revenue mobilisation (DRM). International Developmemt Cooperation; 2018.

9. Williamson RC. Foreign aid and human development: the impact of foreign aid to the health sector. South Econ J. 2008;75(1):188-207.

10. Mishra P, Newhouse D. Does health aid matter? J Health Econ. 2009;28:855-72.

11. Alemayehu W. Aid and the African Dilemma: the effect of foreign aid on human development in Africa [thesis]. Washington, DC: Faculty of the Graduate School of Arts and Sciences, Georgetown University; 2011.

12. Powell-Johnson T, Borghi J, Mueller D, Patouillard E, Mills A. Countdown to 2015: tracking donor assistance to maternal, newborn, and child health. Lancet. 2006;368(9541):1077-87.

13. Shpak S. Effectiveness of foreign aid to health: the case of developing countries [thesis]. Submitted for MA in Economic Analysis, Kyiv: Kyiv School of Economics; 2012. 
14. Chauvet L, Gubert F, Mesple-Somps S. Aid, remittances, medical brain drain and child mortality: evidence using inter and intracountry data. J Dev Stud. 2013;49(6):801-18.

15. Mukherjee D, Kizhakkethalackal ET. Empirics of health aid, education and infant mortality: a semiparametric study. J Appl Econ. 2013;45(22):3137-50.

16. Feeny S, Ouattara B. The effects of health aid on child health promotion in developing countries: cross-country evidence. J Appl Econ. 2013;45(7):911-9.

17. Jamison DT, Summers LH, Alleyne G, Arrow KJ, Berkley S, Binagwaho A, et al. Global health 2035: a world converging within a generation. Lancet. 2013;382(9908):1898-955.

18. Boyle CF, Levin C, Hatefi A, Madriz S, Santos N. Achieving a "grand convergence" in global health: modeling the technical inputs, costs, and impacts from 2016 to 2030. PLoS One. 2015;10(10):e0140092.

19. Heller PS. The prospects of creating 'fiscal space'for the health sector. Health Policy Plan. 2006;21(2):75-9.

20. Okwero P, Tandon A, Sparkes S, Mclaughlin J, Hoogeveen JG. Fiscal space for health in Uganda. World Bank Working Paper No. 186. Washington, DC: World Bank; 2010.

21. Nonvignon J, Aryeetey GC, Novignon J, Kontor K, Almeida S, Wanjala B, CIH. Fiscal implications for health financing in African countries recently graduating from low to lower-middle income status: the case of Ghana and Kenya. Accra: African Health Economics and Policy Association (AfHEA); 2016.

22. Soe-Lin S, Frankel S, Heredia E, Makinen M. Tax reform and resource mobilization for health. Bethesda: Health Finance and Governance Project; 2015.

23. First Universal Health Coverage Financing Forum. Raising Funds for Health: Background Paper. Universal Health Coverage Annual Financing Forum; 2016.

24. International Monetary Fund. Revenue mobilization in developing countries. Washington, DC: International Monetary Fund; 2011.

25. Heller PS. Understanding Fiscal Space. PDP/05/4. Washington, DC: International Monetary Fund; 2005.
26. International Monetary Fund. World revenue longitudinal data. Washington, DC: International Monetary Fund; 2019.

27. International Monetary Fund. World economic outlook. Washington, DC: International Monetary Fund; 2019.

28. Ministry of Health. Health sector holistic assessment of the health sector performance-2015. Accra: Ministry of Health; 2016.

29. Novignon J, Olakojo SA, Nonvignon J. The effects of public and private healthcare expenditure on health status in Sub-Saharan Africa: new evidence from panel data analysis. Health Econ Rev. 2012;2:22.

30. Lawanson AO. Public sector health care financing and health outcomes in Sub-Sharan African countries. In: Olaniyan O, Lawanson AO, Olubajo O, editors. Economics of health sector governance and financing in Nigeria. Ibadan: Ibadan University; 2012. p. $121-48$.

31. Russo G, Bloom G, McCoy D. Universal health coverage, economic slowdown and system resilience: Africa's policy dilemma. BMJ Glob Health. 2017;2(3):1-4.

32. Appiah B. Universal health coverage still rare in Africa. Can Med Assoc J. 2012;184(2):E125-6.

33. Jowett M. Safe motherhood interventions in low-income countries: an economic justification and evidence of cost effectiveness. Health Policy. 2000;53:201-28.

34. Ensor T, Ronoh J. Effective financing of maternal health services: a review of the literature. Health Policy. 2005;75:49-58.

35. Adam T, Lim S, Mehta S, Bhutla Z, Fogstad H, Mathai M, et al. Cost effectiveness analysis of strategies for maternal and neonatal health in developing countries. BMJ. 2005;331(7525):1107.

36. Borghi J, Ensor T, Somanathan A, Lissner C, Mills A. Mobilizing financial resources for maternal health. Lancet. 2006;368:1457-65.

37. Besley T, Persson T. Why do developing countries tax so little? J Econ Perspect. 2014;28(4):99-120. 